As-Syifaa Jurnal Farmasi Desember 2020;12(2):99-106.

ISSN : 2502-9444 (electronic); 2085-4714 (printed)

Journal Homepage : http://jurnal.farmasi.umi.ac.id/index.php/as-syifaa

\title{
PROFIL KADAR GLUKOSA DARAH PASIEN DIABETES MELLITUS TIPE 2 YANG MENGGUNAKAN ATORVASTATIN 20 MG DI RUMAH SAKIT MADANI, ANUTAPURA DAN UNDATA PERIODE 2015-2019
}

\author{
Widya Lestari, Alwiyah Mukaddas
}

Jurusan farmasi, Fakultas Matematika dan Ilmu Pengetahuan Alam, Universitas Tadulako, Palu Email: widy16048@gmail.com

\begin{abstract}
Atorvastatin is one of the lipophilic statins that can cause diabetes through some mechanisms, such as liphophilic properties, it's activities to insulin secretion, insulin signaling, and adiponectin levels. The purpose of this research is to know demographic data, profile of when blood sugar levels, and the time needed for atorvastatin to increase blood sugar when type 2 diabetes mellitus patients use atorvastatin for $20 \mathrm{mg}$. This research is observational descriptive research with retrospective data collection approach by looking at the usage of atorvastatin, with total samples 22 patients obtained from medical record data at Madani hospital, Anutapura and Undata in Palu in the period of 2015-2019. This research result shows that the demographic data of the average age of type 2 diabetes mellitus patients in which complications of dysplidemia that uses atorvastatin for $20 \mathrm{mg}$ are in the age of 45-56 years old, female gender (57.14\%), with the last education of Senior High School (38.09\%) and occupation as Government Employees (33.33\%), the time needed for atorvastatin $20 \mathrm{mg}$ to increase blood sugar is 2 months (the difference is $26.38 \mathrm{mg} / \mathrm{dl}$; percentage 19.52\%) and the percentage of highest blood sugar increase is one year, which is $93.91 \%$.
\end{abstract}

Key words: Atorvastatin, When Blood Glukose, Type 2 Diabetes Mellitus.

\section{PENDAHULUAN}

Penyakit jantung diabetik merupakan penyebab mortalitas tertinggi pada pasien diabetes mellitus. Dimana data riset kesehatan dasar nasional menunjukkan Prevalensi penyakit jantung di Sulawesi Tengah adalah $1,9 \% .{ }^{14}$ Faktor risiko yang turut berperan dalam terjadinya komplikasi kardiovaskular pada pasien DM adalah hiperlipidemia.

Data riset kesehatan dasar nasional menunjukkan bahwa $34,8 \%$ dari penduduk Indonesia yang berusia $\geq 15$ tahun memiliki kadar kolesterol yang abnormal dimana perempuan lebih banyak dari laki-laki dan penduduk daerah perkotaan lebih banyak dibandingkan penduduk di daerah pedesaan. ${ }^{14}$

Statin merupakan terapi lini pertama pada dislipidemia yang direkomendasikan kepada mayotitas pasien dengan berbagai tingkat resiko kardiovaskular. Atorvastatin adalah golongan statin yang berperan dalam mengurangi konsentrasi LDL dengan menghambat 3-hydroxy-3-methyl-glutaryl-CoA Reduktase. ${ }^{4}$ Pengurangan kadar kolestrol yang didalamnya terdapat LDL (Low Density Lipoprotein) mengarah pada pengurangan resiko secara proporsional penyakit kardiovaskular. Semua statin meningkatkan resiko diabetes mellitus. ${ }^{7}$ dapat meningkatkan mobilisasi kalsium intraseluler. ${ }^{22}$ Sehingga menyebabkan masuknya kalsium melalui saluran kalsium tipe-L dan mengakibatkan eksositosis dari butiran yang mengandung insulin $^{2}$ yang mengakibatkan pengurangan sensitivitas insulin ${ }^{5}$ dan juga statin lipofilik dapat memblokir saluran $\mathrm{Ca}^{2+}$ tipe $\mathrm{L}$ dalam sel beta 
yang mengakibatkan penurunan pelepasan insulin. $^{2}$

Peningkatan risiko kenaikan kadar gula darah dan perkembangan DMT2 memang telah dilaporkan dengan penggunaan statin. ${ }^{1}$ Hasil penelitian yang dilakukan oleh yang menyatakan bahwa terdapat 590 pasien $(7,8 \%)$ kejadian onset diabetes dari 7535 pasien yang menggunakan atorvastatin $80 \mathrm{mg}$ dan terdapat 516 pasien $(6,9 \%)$ kejadian onset diabetes dari 7521 pasien menggunakan atorvastatin $10 \mathrm{mg}$ atau simvastatin $10-20 \mathrm{mg}$ selama 4,5 tahun. ${ }^{25}$ $\mathrm{Hal}$ ini didukung oleh studi lain dengan analisis data populasi basis antario di Canada yang dilakukan oleh menyatakan bahwa atorvastatin memiliki peningkatan 22\% dalam resiko diabetes baru diantara jenis statin lainnya. ${ }^{6} \mathrm{Hal}$ ini juga di perkuat oleh studi TNT (Treating to New Targets) dalam yang menyatakan perbandingan atorvastatin $80 \mathrm{mg}$ dan atorvastatin $10 \mathrm{mg}$ menyebabkan onset diabetes masing-masing 418 pasien (11\%) dan 358 pasien $(9,4 \%)$ selama 5 tahun. ${ }^{18}$

Data DMT2 di RSUD Madani Palu tahun 2017 yaitu 858 kasus. Sedangkan data dislipidemia cukup banyak dan cenderung meningkat setiap tahunnya. Untuk data diabetes mellitus di RSUD Undata tahun 2018 -2019 berjumlah 196 kasus. Untuk rumah sakit Anutapura pasien pengguna atorvastatin berjumlah 36 pasien. Jika dibandingkan dengan beberapa rumah sakit di Palu seperti rumah sakit Anutapura, Undata dan Madani, rumah sakit yang menggunakan obat atorvastatin $20 \mathrm{mg}$ sebagai pilihan utama dalam pengobatan dyslipidemia dengan obat golongan statin adalah rumah sakit Madani.

Berdasarkan latar belakang tersebut, maka peneliti tertarik untuk mengetahui pengaruh penggunaan obat golongan statin terutama untuk atorvastatin terhadap glukosa darah sewaktu pasien DMT2 dengan melakukan penelitian secara retrospektif di Rumah Sakit Madani, Anutapura dan Undata periode 2015-2019.

\section{METODE PENELITIAN}

Desain penelitian yang akan dilakukan adalah penelitian deskriptif observasional dengan pendekatan pengambilan data secara retrospektif. dengan mengambil data dari rekam medis pasien diabetes melitus rawat jalan di Rumah sakit Madani, Anutapura, dan Undata kemudian melihat kenaikan glukosa darah sebelum dan sesudah pemakain atorvastatin. Setelah itu dilakukan analisis kualitatif dengan menghitung rata-rata gula darah serta melihat selisih dan presentase gula darah pasien DMT2. Populasi dalam penelitian ini adalah semua pasien DMT2 yang menjalani pengobatan rawat jalan di Rumah Sakit Madani, Anutapura dan Undata. Sampel dalam penelitian ini adalah semua pasien DMT2 yang disertai penyakit penyerta dislipidemia yang menjalani pengobatan rawat jalan di Rumah Sakit Madani, Anutapura dan Undata periode 2015-2019 yang memenuhi kriteria inklusi yaitu Pasien yang menjalani rawat jalan, Pasien diabetes mellitus yang menerima atorvastatin dan Terdapat data pengukuran gula darah puasa lebih dari 1x. kriteria eksklusi yaitu Pasien dengan data tidak lengkap, Pasien yang menerima obat dislipidemia selain atorvastatin, Pasien lost to follow up, Pasien yang menderita cushing (muka bulan), stres akut, feokromasitoma, penyakit hati kronik, defisiensi kalium, penyakit yang kronik, dan sepsis, Addison, gangguan pada ginjal, anorexia nervosa, dan tekanan darah tinggi, Pasien yang mengonsumsi obat-obatan seperti salisilat dosis besar, diuretik tiazid, kortikosteroid, 
Profil Kadar Glukosa Darah Pasien Diabetes Mellitus Tipe 2 Yang Menggunakan Atorvastatin $20 \mathrm{mg}$ di Rumah Sakit Madani, Anutapura Dan Undata Periode 2015-2019

estrogen dan kontrasepsi oral, asam nikotinat, fenotiazin, litium, propranolol, atenolol, cibenzoline dan quinidine, antiinfeksi seperti gatifloxacin, pentamadine, quinine, trimethoprim-sulfamethoxazole.

\section{HASIL DAN PEMBAHASAN}

Karakteristik demografi pasien DMT2 komplikasi dislipidemia yang menjalani rawat jalan di RSUD Madani, Anutapura dan Undata periode 2015-2019.

Tabel 1. Karakteristik demografi

\begin{tabular}{|c|c|c|}
\hline $\begin{array}{l}\text { Karakteristik } \\
\text { Pasien }\end{array}$ & $\begin{array}{c}\text { Jumlah Pasien } \\
(\mathrm{n}=22)\end{array}$ & $\begin{array}{c}\text { Persentase } \\
(\%)\end{array}$ \\
\hline \multicolumn{3}{|l|}{ Usia } \\
\hline 35-44 tahun & 5 & 22.72 \\
\hline 45-54 tahun & 7 & 31.81 \\
\hline 55-64 tahun & 6 & 27.27 \\
\hline$>65$ & 4 & 18.18 \\
\hline \multicolumn{3}{|l|}{ Jenis Kelamin } \\
\hline Perempuan & 13 & 59.09 \\
\hline Laki-laki & 9 & 40.90 \\
\hline \multicolumn{3}{|l|}{ Pendidikan } \\
\hline SD & 4 & 18.18 \\
\hline SMP & 4 & 18.18 \\
\hline SMA & 9 & 40.90 \\
\hline Perguruan Tinggi & 5 & 22.72 \\
\hline \multicolumn{3}{|l|}{ Pekerjaan } \\
\hline Ibu Rumah Tangga & 7 & 31.81 \\
\hline Pegawai Negeri Sipil & 7 & 31.81 \\
\hline Wirasawasta & 5 & 22.72 \\
\hline Swasta & 3 & 13.63 \\
\hline
\end{tabular}

Berdasarkan tabel 1, menunjukan usia pada pasien DMT2 komplikasi dislipidemia yang terbanyak berada direntang 45-54 tahun yaitu berjumlah 7 pasien (31.81\%). Rata-rata usia pasien DMT2 komplikasi dyslipidemia berada pada usia $>40$ tahun. Hasil ini sejalan dengan penelitian yang dilakukan oleh Renata dkk, (2019) menyatakan bahwa Hasil uji statistik menjelaskan terdapat hubungan yang bermakna antara usia dengan kejadian DM Tipe 2. Hal didukung analisis data diperoleh bahwa prevalensi diabetes melitus tertinggi terjadi pada kelompok umur $>45$ tahun sebesar 19,52\%. ${ }^{14}$ Factor resiko DMT2 pada usia $>45$ tahun Secara teori yang dikemukakan bahwa umur sangat erat kaitannya dengan terjadinya kenaikan kadar glukosa darah, sehingga semakin meningkat usia maka prevalensi diabetes dan gangguan toleransi glukosa semakin tinggi. ${ }^{21}$ Semakin bertambahnya usia seseorang, akan terjadi peningkatan intoleransi glukosa dan menyebabkan berkurangnya kemampuan sel pankreas dalam memproduksi insulin. Pada usia tua juga cenderung memiliki gaya hidup yang kurang aktif dan pola makan tidak seimbang sehingga memicu terjadinya resistensi insulin. $^{9}$

Berdasarkan jenis kelamin pada 22 pasien yang menderita DMT2 komplikasi dislipidemia, perempuan adalah jenis kelamin terbanyak berjumlah 13 pasien (59.09\%) diikuti laki-laki berjumlah 9 pasien (40.90\%). Karakteristik demografi responden diabetes mellitus di daerah Surabaya prevalensi terbanyak adalah perempuan (84\%) dan lakilaki (16\%). wanita lebih berisiko mengidap diabetes karena secara fisik wanita memiliki peluang peningkatan indeks masa tubuh yang lebih besar. ${ }^{15}$ Sindroma siklus bulanan (premenstrual syndrome), pasca-menopouse 
yang membuat distribusi lemak tubuh menjadi mudah terakumulasi akibat proses hormonal tersebut sehingga wanita berisiko menderita DMT2. ${ }^{8}$

Berdasarkan tingkat pendidikan menunjukan bahwa tingkat pendidikan SMA adalah yang terbanyak yaitu 9 pasien dengan presentasi 38,09\% pada penderita DMT2. Hubungan Tingkat Sosial Ekonomi : Pendidikan, Penghasilan, Dan Fasilitas Dengan Pencegahan Komplikasi Kronis Pada Penyandang DMT2 Di Surakarta menyatakan bahwa pendidikan responden menunjukkan sebagian besar responden berpendidikan rendah dengan $80,3 \%$ terdiri dari lulus Sekolah Dasar (SD) 26,2\%, Sekolah Menengah Pertama (SMP) sebanyak 9,8\%, dan Sekolah Menengah Akhir (SMA) 44,3\%, untuk pendidikan tinggi yakni hanya 19,7\%. Responden dengan pendidikan rendah (SD, SMP, SMA) pencegahannya dalam komplikasi diabetes mellitus terbilang kurang. Tingkat pengetahuan yang rendah akan dapat memengaruhi pola makan yang salah. Semakin tinggi tingkat pendidikan seseorang maka akan semakin mudah orang tersebut menerima informasi, sehingga umumnya memiliki pemahaman yang baik tentang pentingnya perilaku perawatan diri dan memiliki keterampilan manajemen diri untuk menggunakan informasi peduli diabetes yang diperoleh melalui berbagai media dibandingkan dengan tingkat pendidikan rendah. ${ }^{11}$

Berdasarkan pekerjaan, pada 22 pasien DMT2 komplikasi dislipidemia, pasien dengan pekerjaan lbu Rumah Tangga dan Pegawai Negeri Sipil lebih banyak mengalami DMT2 komplikasi dislipidemia yaitu 7 pasien (31.81\%). Hasil yang didapatkan sesuai bahwa tingkat pekerjaan ringan memiliki presentase lebih besar yaitu $53,48 \%$ dibandingkan dengan tingkat pekerjaan sedang dan berat. Jenis pekerjaan erat kaitannya dengan aktivitas fisik yang dilakukan seseorang, jenis pekerjaan dapat dikelompokkan berdasarkan beratringannya aktivitas fisik yang dilakukan seseorang, dimana kategori ringan diantaranya pegawai kantor, pegawai pegawai tokoh, guru, ibu rumah tangga, ahli hukum dan lain-lain. ${ }^{12}$ Kategori sedang seperti pegawai di industri ringan, mahasiswa, dan militer yang sedang tidak berperang dan kategori berat terdiri dari petani, buruh, militer dalam keadaan latihan, penari, atlet. ${ }^{23}$ Jenis pekerjaan juga erat kaitannya dengan tingkat pendapatan seseorang, tingkat pendapatan dan kemakmuran suatu bangsa dapat mempengaruhi tingginya prevalensi diabetes melitus di negara tersebut yang disebabkan karena adanya perubahan gaya hidup terutama di kota-kota besar. ${ }^{24}$

Berdasarkan tabel 2, Menunjukan bahwa dari 22 pasien DMT2 komplikasi dislipidemia dengan gejala yang sering muncul kebanyakan adalah kram-kram yang berjumlah 14 pasien (63.63\%). Dan diikuti gejala peningkatan tekanan darah yaitu 12 pasien (54.54\%). Kesemutan merupakan gejala yang tidak khas pada DMT2 dengan kata lain kesemutan atau keram-keram merupakan gejala umum yang dirasakan pada penderita DMT2. ${ }^{20}$

Hal ini sesuai dengan penelitian yang dilakukan yang menyatakan bahwa kategori hipertensi stage 1 sebanyak 32\% (18 orang), kategori hipertensi stage 2 sebanyak 25\% (14 orang). ${ }^{17}$ Hipertensi merupakan faktor risiko utama untuk terjadinya DM. ${ }^{10}$ Hubungannya dengan DMT2 sangatlah kompleks, hipertensi 
Profil Kadar Glukosa Darah Pasien Diabetes Mellitus Tipe 2 Yang Menggunakan Atorvastatin $20 \mathrm{mg}$ di Rumah Sakit Madani, Anutapura Dan Undata Periode 2015-2019

dapat membuat sel tidak sensitif terhadap

insulin (resisten insulin). ${ }^{16}$

Kebanyakan juga pasien mengalami

gejala mual, Metformin merupakan obat antidiabetik golongan biguanid yang pada penggunaannya $^{13}$ dapat menimbulkan reaksi efek samping metabolik yaitu hipoglikemia. ${ }^{3}$ Mekanisme potensi hipoglikemia diinduksi Metformin termasuk penurunan produksi glukosa hepatik dan penurunan penyerapan glukosa.

Penggunaan Glimepirid dapat memicu terjadinya reaksi efek samping berupa rasa mual (nausea) dan muntah (vomiting). Timbulnya mual, tremor, dan pusing, merupakan gejala awal dari hipoglikemia akibat penggunaan obat golongan Sulfonilurea.

Tabel 2. Karakteristik klinis

\begin{tabular}{lcc}
\hline \multicolumn{1}{c}{ Manifestasi Klinik } & Jumlah Pasien (n=22) & Persentase (\%) \\
\hline Peningkatan tekanan darah & 12 & 54.54 \\
Kram-kram & 14 & 63.63 \\
Mual & 7 & 31.81 \\
Nyeri kaki & 6 & 27.27 \\
Nyeri dada & 3 & 13.63 \\
Pusing & 3 & 13.63 \\
Sesak & 2 & 9.09 \\
Sering buang air kecil & 1 & 4.54 \\
Susah tidur & 1 & 4.54 \\
Nyeri lutut & 1 & 4.54 \\
Memar & 1 & 4.54 \\
Bengkak kaki & 1 & 4.54 \\
Berat bahu & 1 & 4.54 \\
\hline
\end{tabular}

Tabel 3. Profil kadar glukosa darah sewaktu sebelum dan setelah penggunaan obat atorvastatin $20 \mathrm{mg}$ pada pasien DMT2 komplikasi dislipidemia yang menjalani rawat jalan di Rumah Sakit Madani, Anutapura dan Undata kota Palu periode 2015-2019.

\begin{tabular}{|c|c|c|c|c|}
\hline \multirow{2}{*}{ Waktu Pemakaian } & \multirow{2}{*}{$\begin{array}{c}\text { Kategori Kadar } \\
\text { GDS }\end{array}$} & \multicolumn{2}{|c|}{ Rata-rata (mg/dL) } & \multirow{2}{*}{$\begin{array}{c}\text { Persentase } \\
(\%)\end{array}$} \\
\hline & & Nilai Kadar GDS & Selisih & \\
\hline \multirow{2}{*}{$\begin{array}{l}1 \text { bulan } \\
(n=12)\end{array}$} & Sebelum & 188.45 & \multirow{2}{*}{-7.64} & \multirow{2}{*}{-4.05} \\
\hline & Sesudah & 180.81 & & \\
\hline \multirow{2}{*}{$\begin{array}{l}2 \text { bulan } \\
(n=7)\end{array}$} & Sebelum & 135.14 & \multirow{2}{*}{26.38} & \multirow{2}{*}{19.52} \\
\hline & Sesudah & 161.52 & & \\
\hline \multirow{2}{*}{$\begin{array}{l}3 \text { bulan } \\
(n=11)\end{array}$} & Sebelum & 145.45 & \multirow{2}{*}{19.9} & \multirow{2}{*}{13.68} \\
\hline & Sesudah & 165.35 & & \\
\hline \multirow{2}{*}{$\begin{array}{l}4 \text { bulan } \\
(n=8)\end{array}$} & Sebelum & 135.25 & \multirow{2}{*}{37.36} & \multirow{2}{*}{27.62} \\
\hline & Sesudah & 172.61 & & \\
\hline \multirow{2}{*}{$\begin{array}{l}5 \text { bulan } \\
(n=6)\end{array}$} & Sebelum & 232.66 & \multirow{2}{*}{-23} & \multirow{2}{*}{-9.88} \\
\hline & Sesudah & 209.66 & & \\
\hline \multirow{2}{*}{$\begin{array}{l}6 \text { bulan } \\
(n=6)\end{array}$} & Sebelum & 167 & \multirow{2}{*}{18} & \multirow{2}{*}{10.77} \\
\hline & Sesudah & 185 & & \\
\hline \multirow{2}{*}{$\begin{array}{l}7 \text { bulan } \\
(n=6)\end{array}$} & Sebelum & 171.71 & \multirow{2}{*}{-4.85} & \multirow{2}{*}{-2.82} \\
\hline & Sesudah & 166.86 & & \\
\hline
\end{tabular}


Profil Kadar Glukosa Darah Pasien Diabetes Mellitus Tipe 2 Yang Menggunakan Atorvastatin $20 \mathrm{mg}$ di Rumah Sakit Madani, Anutapura Dan Undata Periode 2015-2019

\begin{tabular}{|c|c|c|c|c|}
\hline \multirow{2}{*}{ Waktu Pemakaian } & \multirow{2}{*}{$\begin{array}{c}\text { Kategori Kadar } \\
\text { GDS }\end{array}$} & \multicolumn{2}{|c|}{ Rata-rata $(\mathrm{mg} / \mathrm{dL})$} & \multirow{2}{*}{$\begin{array}{c}\text { Persentase } \\
(\%)\end{array}$} \\
\hline & & Nilai Kadar GDS & Selisih & \\
\hline \multirow{2}{*}{$\begin{array}{l}8 \text { bulan } \\
(\mathrm{n}=4)\end{array}$} & Sebelum & 169 & \multirow{2}{*}{-41.25} & \multirow{2}{*}{-24.4} \\
\hline & Sesudah & 127.75 & & \\
\hline \multirow{2}{*}{$\begin{array}{c}9 \text { bulan } \\
(\mathrm{n}=5)\end{array}$} & Sebelum & 196 & \multirow{2}{*}{12.6} & \multirow{2}{*}{6.42} \\
\hline & Sesudah & 208.6 & & \\
\hline \multirow{2}{*}{$\begin{array}{l}10 \text { bulan } \\
(\mathrm{n}=4)\end{array}$} & Sebelum & 169.5 & \multirow{2}{*}{-19.5} & \multirow{2}{*}{-11.5} \\
\hline & Sesudah & 150 & & \\
\hline \multirow{2}{*}{$\begin{array}{c}11 \text { bulan } \\
(n=4)\end{array}$} & Sebelum & 108.5 & \multirow{2}{*}{38.75} & \multirow{2}{*}{35.71} \\
\hline & Sesudah & 147.25 & & \\
\hline \multirow{2}{*}{$\begin{array}{c}1 \text { tahun } \\
(\mathrm{n}=7)\end{array}$} & Sebelum & 166.61 & \multirow{2}{*}{93.91} & \multirow{2}{*}{56.36} \\
\hline & Sesudah & 260.52 & & \\
\hline \multirow{2}{*}{$\begin{array}{c}2 \text { tahun } \\
(\mathrm{n}=4)\end{array}$} & Sebelum & 106.5 & \multirow{2}{*}{31.5} & \multirow{2}{*}{29.57} \\
\hline & Sesudah & 138 & & \\
\hline
\end{tabular}

Dari tabel 3, menunjukkan nilai ratarata kadar gula darah sewaktu pada pasien DMT2 komplikasi dislipidemia sebelum dan sesudah menggunakan atorvastatin selama 2 tahun. Pada pasien yang menggunakan atorvastatin $20 \mathrm{mg}$ peningkatan kadar gula darah sewaktu terjadi pada 2 bulan pemakaian dari sebelum pemakaian $135.14 \mathrm{mg} / \mathrm{dL}$ menjadi $161.52 \mathrm{mg} / \mathrm{dL}$ dengan selisih peningkatan
$26.38 \mathrm{mg} / \mathrm{dL}$ dan presentasi peningkatan sebesar $19.52 \%$. Peningkatan kadar gula darah sewaktu yang tinggi terjadi pada 1 tahun pemakaian dengan kadar gula darah sewaktu sebelum pemakaian atorvastatin $20 \mathrm{mg}$ yaitu $166.61 \mathrm{mg} / \mathrm{dL}$ menjadi $260.52 \mathrm{mg} / \mathrm{dL}$ dengan selisih $93.91 \mathrm{mg} / \mathrm{dL}$ dan presentasi peningkatan sebesar $56.36 \%$.

Tabel 4. Review Jurnal Penelitian

\begin{tabular}{|c|c|c|c|c|}
\hline Jurnal & Ras/Negara & Tahun & Jumlah Sampel & Hasil \\
\hline $\begin{array}{l}\text { N. Sattar et } \\
\text { al., } 2010\end{array}$ & $\begin{array}{l}\text { meta analisis (italia, } \\
\text { norwegia, amerika } \\
\text { serikat, jepang }\end{array}$ & 1 tahun & $\begin{array}{l}\text { Total sampel } 7773 \\
\text { pasien non diabetes; } \\
3910 \text { terapi } \\
\text { atorvastatoin } 10 \mathrm{mg} ; \\
3863 \text { plasebo. }\end{array}$ & $\begin{array}{l}\text { kasus baru diabetes mellitus } \\
288 \text { kasus; } 154(3.9 \%) \text { kasus } \\
\text { terjadi pada kelompok statin; } \\
134 \text { (3.5\%) kasus kelompok } \\
\text { plasebo. Dengan presentase } \\
\text { kenaikan GDP } 7.07 \% \text {. }\end{array}$ \\
\hline $\begin{array}{l}\text { Waters et al., } \\
2013\end{array}$ & Amerika serikat & 4 tahun & $\begin{array}{ll}\text { atorvastatin } & 80 \\
\text { mg(590 pasien) }\end{array}$ & $\begin{array}{lcc}\text { Baseline } & \text { GDP }(107.9 \mathrm{mg} / \mathrm{dl}) \text {, } \\
\text { sesudah } & \text { terapi } & \text { GDP }(126 \\
\mathrm{mg} / \mathrm{dl}) ; & \text { selisih } & \text { GDP }(18.1 \\
\mathrm{mg} / \mathrm{dl}) ; \text { presentase }(16.77 \%)\end{array}$ \\
\hline $\begin{array}{c}\text { Waters et al., } \\
2011\end{array}$ & Scotlandia & 5 tahun & $\begin{array}{l}\text { Atorvastatin } 80 \mathrm{mg} \\
\text { (166 pasien) }\end{array}$ & $\begin{array}{lcc}\text { Baseline } & \text { GDP }(103.5 \mathrm{mg} / \mathrm{dl}) \text {; } \\
\text { sesudah } & \text { terapi } & \text { GDP }(126 \\
\mathrm{mg} / \mathrm{dl}) ; & \text { selisih } & \text { GDP }(22.5 \\
\mathrm{mg} / \mathrm{dl}) ; \text { presentase }(21.73 \%)\end{array}$ \\
\hline Dian, 2019 & Indonesia (Palu) & 3 bulan & $\begin{array}{l}13 \text { pasien terapi } \\
\text { simvastatin } 10 \mathrm{mg} \\
\text { dan } 13 \text { pasien terapi } \\
\text { simvastatin } 20 \mathrm{mg}\end{array}$ & $\begin{array}{l}\text { Terapi simvastatin } 10 \\
\text { mg(Presentase GDP } 10.05 \% \text { ) } \\
\text { Terapi simvastatin } 20 \\
\text { mg(Presentase GDP } 14.40 \% \text { ) }\end{array}$ \\
\hline $\begin{array}{c}\text { Hydrie et al., } \\
2007\end{array}$ & Pakistan & 3 bulan & $\begin{array}{l}50 \text { pasien menerima } \\
\text { simvastatin } 40 \mathrm{mg} \\
\text { dan } 50 \text { pasien } \\
\text { sebagai kelompok } \\
\text { kontrol }\end{array}$ & $\begin{array}{l}\text { Baseline GDP }(153.55 \mathrm{mg} / \mathrm{dl}) \text {; } \\
\text { sesudah terapi GDP }(147.95 \\
\mathrm{mg} / \mathrm{dl}) \text {. Selisih GDP }(5.6 \mathrm{mg} / \mathrm{dl}) \text {; } \\
\text { presentase GDP }(3.64 \%)\end{array}$ \\
\hline $\begin{array}{l}\text { Crandall et } \\
\text { al., } 2017\end{array}$ & $\begin{array}{l}\text { Amerika serikat } 59 \% ; \\
\text { asia-amerika } 3 \% ; \\
\text { afrika-amerika } 21 \% ; \\
\text { amerika-india } 3 \%\end{array}$ & 3 tahun & $\begin{array}{l}\text { pengguna statin(444 } \\
\text { pasien) tidak } \\
\text { menggunakan } \\
\text { statin(629 pasien) }\end{array}$ & $\begin{array}{l}\text { Two-hour glucose }(\mathrm{mg} / \mathrm{dL}) \text { : } \\
\text { Pengguna statin(166 } \mathrm{mg} / \mathrm{dL}) \text {; } \\
\text { tanpa statin }(164 \mathrm{mg} / \mathrm{dL}) \text {. }\end{array}$ \\
\hline
\end{tabular}


Dari berbagai penelitian yang telah dilakukan semua golongan statin dapat meningkatkan kadar glukosa darah. Seperti halnya atorvastatin dengan variasi dosis yaitu $10 \mathrm{mg}$ dan $80 \mathrm{mg}$ meningkatkan kadar GDP masing-masing $7.07 \%$ (1 tahun), $16.77 \%$ (4 tahun) dan $21.73 \%$ (5 tahun). Sedangkan untuk simvastatin yang merupakan golongan yang sama dengan atorvastatin, dengan dosis 10 $\mathrm{mg}, 20 \mathrm{mg}$ dan $40 \mathrm{mg}$ dapat memicu peningkatan kadar GDP dengan masingmasing presentase yaitu $10.05 \%$ (3 bulan), $14.40 \%$ (3 bulan) dan 3.64\% (3 bulan). Sehingga perbedaan hasil yang didapatkan dapat disebabkan karena jumlah sampel, dosis obat yang berbeda, perbedaan individu dan waktu terapi obat yang digunakan.

\section{BATASAN PENELITIAN}

Adapun keterbatasan dalam penelitian ini adalah jumlah sampel yang tidak mencukupi untuk dilakukan analisis statistik yang disebabkan karena banyaknya rekam medik yang hancur dan hilang pasca bencana dan data pasien yang tidak lengkap dan keterbatasan obat yang disebabkan mahalnya harga atorvastatin sehingga penggunaan atorvastatin di rumah sakit kurang diresepkan.

\section{KESIMPULAN}

Berdasarkan data demografi yang diperoleh 'usia, Jenis kelamin dan pekerjaan mempengaruhi terjadinya DMT2. Dimana terdapat peningkatan glukosa darah sewaktu yang diawali pada pemakaian 2 bulan dan selama pemakaian 2 tahun. Sehingga atorvastatin $20 \mathrm{mg}$ yang digunakan oleh 22 sampel pasien dapat meningkatkan glukosa darah sewaktu.

\section{SARAN}

Sebaiknya penelitian selanjutnya untuk penelitian secara retrospektif harus melakukan observasi terlebih dahulu agar nantinya data yang diperoleh sesuai dengan ketentuan penelitian, dan untuk penelitian atorvastatin mempengaruhi kadar gula darah sebaiknya dilakukan secara prospektif.

\section{DAFTAR PUSTAKA}

1. ADA. American Diabetes Association Standards Of Medical Care In Diabetes. Diabetes Care. 2018; 41(9): 2045-2047.

2. Aiman U, Najmi $A$, and Khan R. Statin induced diabetes and its clinical implications. Journal of Pharmacology and Pharmacotherapeutics. 2014;5(3):181.

3. Al-Abri SA, Hayashi S, Thoren KL, Olson KR. Metformin overdose-induced hypoglycemia in the absence of other antidiabetic drugs. Clinical Toxicology. 2013;51(5): 444-447

4. Atalla MM, Hamed ER, and El-Shami AR. Optimization of a culture medium for increased mevinolin production by Aspergillus terreus strain. Malaysian Journal of Microbiology 2008; 4(2).

5. Baker WL, Talati R, White CM, and Coleman $\mathrm{Cl}$. Differing effect of statins on insulin sensitivity in non-diabetics: A systematic review and meta-analysis. Diabetes Research and Clinical Practice. 2010; 87(1): 98-107.

6. Carter AA, Gomes T, Camacho X, N Juurlink D, R Shah B, and M Mamdani M. Risk of incident diabetes among patients treated with statins: 2013; population based study. BMJ. 2013; 346:f2610:1-11.

7. Culver AL, Ockene IS, Balasubramanian R, Olendzki BC, Sepavich DM, WactawskiWende J, Ma Y. Statin use and risk of diabetes mellitus in postmenopausal women in the Women's Health Initiative. Archives of Internal Medicine. 2012;172(2):144-152.

8. Damayanti L. Diabetes dan Hipertensi Wanita Lebih Berisiko [http://www.herbalitas.com/ diabeteshipertensiwanita-lebih-beresiko/]. 2010. diakses pada tanggal 22 November 2019.

9. Saputra EV. Respons Akut Shiatsu dan Refleksi terhadap Kadar Glukosa Darah 
Penderita Diabetes Melitus Tipe Dua. $2017 . \quad$ Retrieved from journal.student.uny.ac.id/ojs/index.php/ikor a/article/download/8808/8467

10. Gibney MJ, Kearney BM, Arab MJL. Gizi Kesehatan Masyarakat. Jakarta: EGC. 2009.

11. Hakim DL. Hubungan Tingkat Sosial Ekonomi: Pendidikan, Penghasilan, dan Fasilitas dengan Pencegahan Komplikasi Kronis Pada Penyandang Diabetes Melitus Tipe 2 (Skripsi). Surakarta. Fakultas IImu Kesehatan Universitas Muhammadiyah Surakarta, 2018.

12. Irawan D. Prevalensi dan Faktor Risiko Kejadian Diabetes Melitus Tipe 2 di Daerah Urabn Indonesia. Universitas Indonesia 2010; 1-121. Retrieved from http://lib.ui.ac.id/file?file=digital/20267101T 28492-Prevalensi dan faktor-full text.pdf

13. Putra RJS, Achmad A, Pramestutie PH. Kejadian Efek Samping Potensial Terapi Obat Anti Diabetes Pada Pasien Diabetes Melitus Berdasarkan Algoritme Naranjo. Pharmaceutical Journal of Indonesia. 2017; 2(2):45-50.

14. Kementrian kesehatan Republik Indonesia. Laporan Nasional Riset Kesehatan Dasar 2018. 2018.

15. Kusnanto K, Sundari PM, Asmoro CP, Arifin $\mathrm{H}$. Hubungan Tingkat Pengetahuan Dan Diabetes Self-Management Dengan Tingkat Stres Pasien Diabetes Melitus Yang Menjalani Diet. Jurnal Keperawatan Indonesia, 2019; 22(1):31-42. https://doi.org/10.7454/jki.v22i1.780

16. Mihardja, L. Faktor yang Berhubungan dengan Pengendalian Gula Darah pada Penderita Diabetes Mellitus dalam Majalah Kedokteran Indonesia. Jakarta. 2009.

17. Mutmainah I. Hubungan Kadar Gula Darah dengan Hipertensi Pada Penderita Diabetes Melitus Tipe 2 di Rumah Sakit Umum Daerah Karanganyar (Skripsi).
Surakarta. Fakultas Kedokteran Universitas Muhammadiyah Surakarta, 2012.

18. Navarese EP, Buffon A, Andreotti F, Kozinski M, Welton N, Fabiszak T, Kubica J. Meta-Analysis Of Impact of Different Types And Doses of Statins on New-Onset Diabetes Mellitus. American Journal of Cardiology. 2013; 111(8):1123-1130.

19. PERKI.Panduan Tatalaksana Dislipidemia. Jakarta. Perhimpunan Dokter Spesialis Kardiovaskular Indonesia, 2017.

20. Putri RI. Faktor Determinan Nefropati Diabetik pada Penderita Diabetes Melitus di RSUD DR. M. Soewandhie Surabaya. Jurnal Berkala Epidemiologi. 2015;3(1):109-121.

21. Smeltzer SC, Bare BG. Buku Ajar Kesehatan Medical Bedah, Volume 2, Edisi 8. Jakarta: Buku Kedokteran EGC, 2008.

22. Stancu C, Sima A. Statins: mechanism of action and effects. J Cell Mol Med. 2001;5(4):378-87.

23. Sukardji K. Penatalaksanaan Gizi pada Diabetes Melitus, dalam Buku Penatalaksanaan Diabetes Melitus Terpadu (Panduan Penatalaksanaan Diabetes Melitus bagi Dokter dan Edukator). Edisi ke-2, Cetakan ke-7. Jakarta: Balai Penerbit FKUI, 2009.

24. Suyono, S. Patofisiologi Diabetes Melitus, dalam Buku Penatalaksanaan Diabetes Melitus Terpadu (Panduan Penatalaksanaan Diabetes Melitus bagi Dokter dan Edukator). Edisi ke-2, Cetakan ke-7. Jakarta: Balai Penerbit FKUI, 2009.

25. Waters DD, Ho JE, Boekholdt SM, Demicco DA, Kastelein JJP, Messig M, Pedersen TR. Cardiovascular event reduction versus new-onset diabetes during atorvastatin therapy: Effect of baseline risk factors for diabetes. Journal of the American College of Cardiology. 2013; 61(2):148-152 